\section{Une pneumonie varicelleuse}

\section{Chicken Pox Pneumonia}

\section{Guez $\cdot$ S. Dautheville $\cdot$ P. Ray}

Reçu le 19 mars 2014; accepté le 16 août 2014

(C) SFMU et Lavoisier SAS 2014

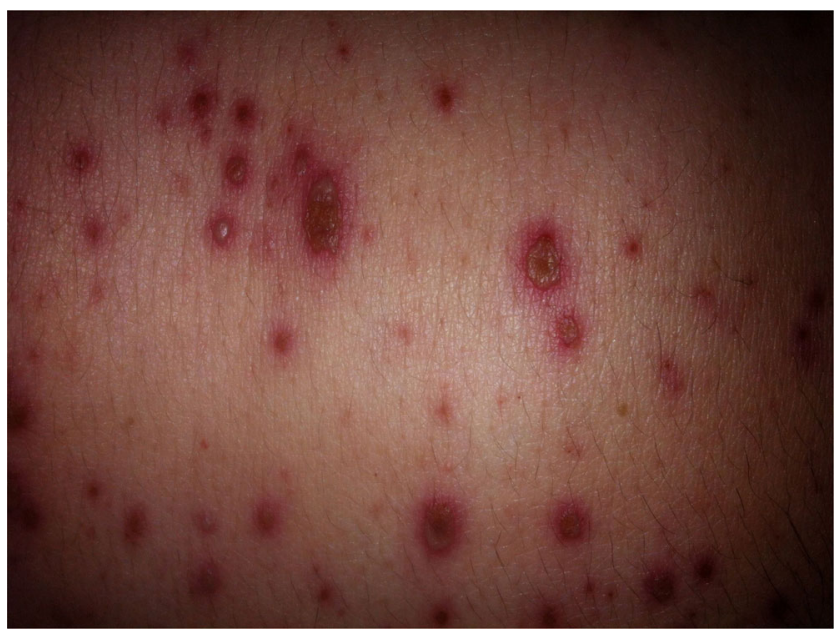

Fig. 1 Lésions érythémato-vésiculeuses prurigineuses, d'âge différent et ombiliquées

Un patient de 55 ans consulte pour dyspnée dans un contexte de lésions cutanées (Fig. 1) diffuses (dont le cuir chevelu) et muqueuses (bouche) évocatrices de varicelle évoluant depuis quatre jours. Le syndrome alvéolointerstitiel à la radiographie pulmonaire (Fig. 2) suggère le

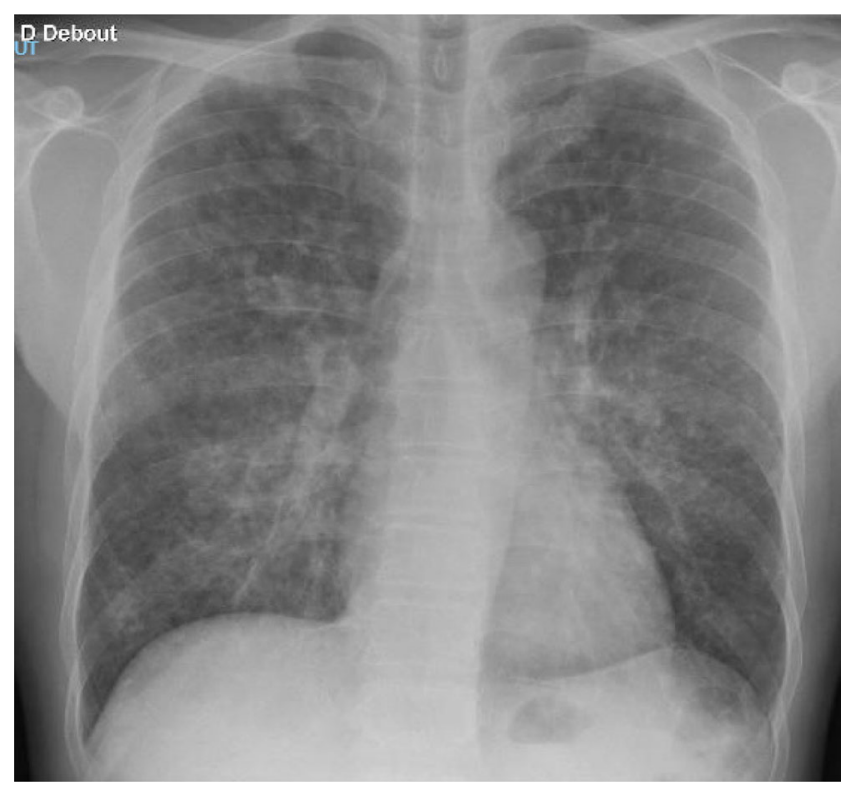

Fig. 2 Radiographie thoracique de face montrant le syndrome alvéolo-interstitiel diffus et bilatéral

diagnostic de pneumopathie varicelleuse chez ce patient immunocompétent.
C. Guez $\cdot$ S. Dautheville $\cdot$ P. Ray $(\square)$

Service d'accueil des urgences, CHU Tenon,

Assistance publique-hôpitaux de Paris, 55, rue Pelleport,

F-75020, Paris, France

e-mail : patrick.ray@tnn.aphp.fr

P. Ray

Sorbonne Universités UMPC, Univ Paris 06, Paris, France 